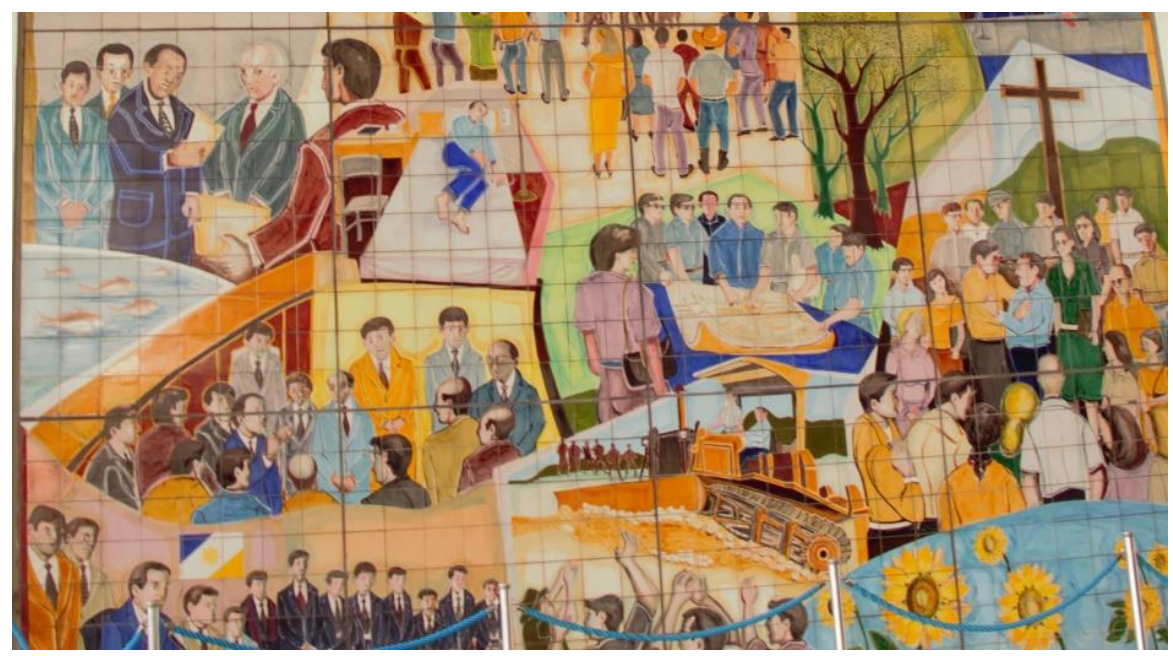

\title{
A praça é nossa! Narrativas cotidianas e pedagogias culturais
}

The square is ours! Daily narratives and cultural pedagogies

\author{
Amanda M. P. Leite ${ }^{1}$ \\ http://orcid.org/0000-0002-5335-6428
}

\begin{abstract}
Resumo
Quando a aula acontece na praça o que ela pode provocar? O texto procura pensar sobre a importância das Pedagogias Culturais a partir de aulas realizadas na Praça dos Girassóis, na cidade Palmas/TO, entre monumentos e símbolos arquitetônicos da paisagem urbana. Tal exercício de pensamento só é possível por entender que as Pedagogias Culturais acontecem também fora das salas de aula acadêmicas e que os espaços de ensino podem surgir em diferentes lugares, como é o caso da ocupação da praça como cenário de aulas de Didática para estudantes de Pedagogia da Universidade Federal do Tocantins. Ocupamos a praça como lócus de investigação. Tomamos a cidade, suas narrativas para observar aprendizagens que se entrelaçam à cultura, à vida e ao próprio cotidiano da cidade, daí que quando mediadas pela Pedagogia podem construir conhecimento. Um movimento decorrente dos Estudos Culturais.
\end{abstract}

Palavras-chave: Aula; Praça dos Girassóis; Didática; Estudos Culturais; Pedagogias Culturais

\section{Abstract}

When the class happens in the square what can it provoke? The text tries to think about the importance of Cultural Pedagogies from classes held in the Square of Sunflowers, in the city Palmas / TO, between monuments and architectural symbols of the urban landscape. Such an exercise of thought is only possible because it understands that Cultural Pedagogies also happen outside the academic classrooms and that the educational spaces can arise in different places, as is the case of the occupation of the square as scenario of didactic classes for students of Pedagogy of the Federal University of Tocantins. We occupy the square as a locus of investigation. We take the city, its narratives to observe learning that intertwined with culture, life and the daily life of the city, which when mediated by Pedagogy can build knowledge. A movement derived from Cultural Studies.

Keywords: Classroom; Sunflowers Square; Didactics; Cultural Studies; Cultural Pedagogies

1 Professora do Programa de Pós-graduação em Comunicação e Sociedade (UFT). E-mail: amandaleite@mail.uft.edu.br 


\section{Introdução}

Quando a aula de Didática acontece na praça, o que ela pode provocar? Neste artigo procuro pensar sobre a importância das Pedagogias Culturais a partir de aulas realizadas na Praça dos Girassóis, entre monumentos e símbolos arquitetônicos da paisagem urbana da cidade Palmas/TO. Tal exercício de pensamento só é possível por entender que as Pedagogias Culturais acontecem também fora das salas de aulas escolares e acadêmicas, e que os espaços de ensino e de aprendizagem podem surgir em diferentes lugares, como é o caso da ocupação da praça como cenário de aulas para estudantes de Pedagogia, da Universidade Federal do Tocantins (UFT).

Desejo pensar também a invenção da última capital brasileira. O que proponho é um exercício de olhar: olhar e ver/ver e pensar. Convido você leitor a passear pela Praça dos Girassóis, um dos principais atrativos da cidade. No percurso vamos identificar as transformações ocorridas no cerrado tocantinense e questionar o modo como percebemos a invenção da cidade, seus espaços, sua rotina, suas narrativas, seus eventos e acasos. Um pensamento que se desdobra de pesquisas realizadas junto ao Coletivo 50 Graus - Grupo de Pesquisa e Prática Fotográfica ${ }^{2}$, assim como de diálogos forjados no encontro com acadêmicos do curso de Pedagogia/UFT.

Ocupamos a praça como lócus de investigação e partilha. Ao tomar a cidade e perceber as suas narrativas é possível observar que a questão do ensino e da aprendizagem está entrelaçada a cultura, a vida e ao próprio cotidiano da cidade, daí que quando mediadas pela Pedagogia (e neste caso pelos debates didáticos) podem construir conhecimento. Uma investida decorrente dos Estudos Culturais (EC) ou uma possibilidade de compreender os processos educativos que nos constituem por outras vias. Um modo de explorar diferentes saberes na busca por outras pedagogias. Para Costa (2015, p. 61) os Estudos Culturais configuram "um profícuo espaço de análise sobre a produtividade das Pedagogias Culturais na constituição de sujeitos, na composição de identidades, na disseminação de práticas e condutas [...] no delineamento de formas de ser e viver na contemporaneidade" (COSTA, 2015, p. 61).

Assim, além do pensamento articulado aos Estudos Culturais, proponho pensar o (des)aparecimento de certas paisagens na produção do cotidiano ou, mais precisamente, na invenção do espaço urbano. Qual é a identidade que Palmas anuncia como sua? O que

\footnotetext{
${ }^{2}$ https://coletivo50graus.wixsite.com/fotografia
} 
vemos nas mesclas entre o cerrado e a invenção desta cidade? O que revelam seus momentos e símbolos históricos?

Diante das inúmeras possibilidades de pensar a nossa relação com a praça e as articulações educativas possíveis, delimito a questão a ser tratada aqui para que o leitor se situe melhor neste trajeto, ou seja, quando a aula (de Didática) acontece na praça, o que ela pode provocar? Na tentativa de responder, não para silenciá-la, ao contrário, para ampliar o pensamento sobre a temática, trago como aprofundamento teórico as contribuições das Pedagogias Culturais (dadas pelos monumentos e símbolos arquitetônicos da praça). Como anunciado anteriormente, nestas aulas, tomamos a cidade e suas narrativas para observar que as aprendizagens se entrelaçam à cultura, à vida e ao próprio cotidiano da cidade, elas constroem diferentes conhecimentos.

Elejo os Estudos Culturais (EC) como abordagem metodológica, pois além de se tratar de uma corrente de pensamento teórico e conceitual importante sobre a cultura contemporânea, também pode ser considerado como uma metodologia científica. Poderíamos apresentar ainda uma lista grande de autores que abordam sobre as Pedagogias Culturais e os Estudos Culturais, mas, afim de delimitar o diálogo, os referenciais teóricos que irão auxiliar aqui a realizar procedimentos analíticos a partir da temática são: Paula Andrade e Marisa Vorraber Costa (2015); Henry Girouux (1999); Shirley Steinberg (1997); Eugênio Firmino (2003) e Marcos Villas Boas (2002).

Por fim, se a cultura consiste numa fabricação de signos, significados e sentidos ela também nos constitui, ou seja, produz em nós uma formação cultural dada na vida, nas redes e práticas sociais. Para Stuart Hall (1997, p. 06) "não pode mais ser estudada como uma variável sem importância, secundária e dependente em relação ao que faz o mundo mover-se; tem de ser vista como algo fundamental, constitutivo, determinando tanto a forma como o caráter deste movimento, bem como a sua vida interior".

\section{Palmas e a Praça dos Girassóis}

Nas margens do Rio Tocantins nasce a "caçula das capitais" brasileira, Palmas/Tocantins. Com apenas 27 anos, a cidade tem pessoas vindas de todos os lugares do Brasil e hoje contabiliza em torno 228.332 habitantes. Os dados do IBGE mostram que é a cidade que mais cresce geometricamente no país, cerca de 2, 91\% correspondente ao período de 2013-2014. Palmas é uma cidade planejada à moda de Brasília. As enormes fazendas que margeavam o Rio Tocantins, as pequenas vilas, as praias sazonais parecem terem sido "engolidas" pelas águas ou pela promessa de futuro para a região norte. Surge 
a "capital das oportunidades" instalada estrategicamente no coração selvagem do Brasil. Bioma: Cerrado.

Inaugurada no ano 2000, a Praça dos Girassóis é um dos orgulhos tocantinenses. Considerada a maior praça das Américas e a $2^{\mathrm{a}}$ Maior do mundo, está localizada no Centro Geodésico do Brasil ${ }^{3}$. Sua dimensão impressiona turistas e moradores ao registrar a área de $571.000 \mathrm{~m}^{2}$, pouco mais de $3 \mathrm{~km}$ de extensão (que corresponde a uma volta completa na praça). Está no cruzamento das principais avenidas da cidade, a Av. Theotônio Segurado e Av. Juscelino Kubitschek (JK). Embora a praça receba o nome de uma flor tropical - o girassol - quase não encontramos girassóis plantados na praça (exceto em ocasiões festivas na cidade).

Na página oficial do governo do estado do Tocantins temos a seguinte definição:

[...] projetada para abrigar o centro das decisões dos Poderes Executivo, Legislativo e Judiciário do Tocantins, a Praça dos Girassóis, em Palmas, é a maior praça da América Latina e a segunda maior do mundo, perdendo em tamanho apenas para a Praça Merdeka, na Indonésia. Aos palmenses a importância da Praça dos Girassóis vai mais além, afinal, foi nesse grande espaço que teve início a história da construção da capital mais jovem do País. Passear pela Praça é conhecer um pouco mais sobre a história e a cultura da cidade e do Tocantins.

Praça dos Girassóis, cartão-postal do cerrado. No chão, temos símbolos desenhados com pedras portuguesas coloridas, que fazem referência às etnias indígenas do estado do Tocantins, sendo: Apinajé, Khahô e Xambioá. Também encontramos as sedes administrativas dos poderes Executivo, Legislativo e Judiciário além de outros marcos arquitetônicos de Palmas presentes na praça. Por ser de grande extensão os habitantes da cidade usam este espaço para shows, apresentações culturais e práticas esportivas.

A praça é também um museu aberto em que é possível percorrer parte da história da criação da capital através de monumentos e símbolos, dentre os quais destaco: o Palácio Araguaia, o Cruzeiro, a Súplica dos Pioneiros; a Cascata, o Monumento 18 do Forte de Copacabana, o Relógio de sol, A Rosa dos Ventos, o Monumento à Bíblia, a Praça Khahô e o Memorial Coluna Prestes.

Diante das transformações ocorridas no cerrado norte-central, é curioso observar a "pressa" da cidade em alcançar um ar de metrópole e/ou uma identidade (quase)

\footnotetext{
${ }^{3}$ Curiosamente sobre isto há controvérsias, pois a capital do estado de Mato Grosso, Cuiabá, também anuncia que o Centro Geodésico do Brasil passa por lá.
} 
cosmopolita. A região que antes era majoritariamente constituída por pessoas vindas do Pará, Maranhão, Goiás, Piauí, Mato Grosso e Bahia (estados que fazem fronteira com o Tocantins) e ainda por comunidades indígenas e quilombolas, hoje faz outro percurso, move-se por traços urbanísticos taticamente marcados.

O que nos é visível nos faz questionar e desejar pensar os sentidos e significados históricos que as transformações $d a /$ na cidade sugerem especialmente, as narrativas contemporâneas tecidas da/na/pela/com a praça. Gostaria de explorar aqui todos os monumentos presentes na praça, mas como são muitos e neste artigo não terei espaço para tanto, elejo os que tenho abordado nas aulas de Didática e que, em minha compreensão, merecem um exercício de pensamento mais denso e especial leitura.

\section{Monumentos e símbolos}

A cidade, suas manifestações e expressões artísticas fomentam uma determinada narrativa sobre a construção de capital mais jovem do Brasil. Palmas/TO nasce ligada à figura de um herói, Siqueira Campos, o desbravador do norte-central. Siqueira aparece nas falas dos habitantes mais antigos ou mesmo na fala de acadêmicos de Pedagogia, como um líder que lutou avidamente para dividir o norte do estado de Goiás e criar o estado do Tocantins.

É interessante observar que, embora geograficamente o Tocantins fique no mesmo alinhamento dos estados centrais do Brasil, por ser a "antiga" região norte do estado de Goiás, considerada desprivileigiada em termos de recursos financeiros e investimentos em relação aos estados do sudeste e do sul do país, ao criar o novo estado, foi mais estratégico demarcá-lo como região norte ou como o Portal da Amazônia Legal, para assegurar questões políticas e financeiras. Sem mencionar o fato de que a construção de uma cidade/capital no cerrado se configuraria também como um marco, uma promessa histórica de mudança para a região norte, em nível local, nacional e internacional uma vez que se almejava estreitar as relações com o Peru, a Venezuela, as Guianas e a Bolívia.

Nasce a cidade e com ela nasce o mito de um herói. Esta narrativa se propaga tanto no imaginário popular quanto nos monumentos e símbolos presentes na Praça dos Girassóis e nos museus da cidade. E não seria nenhum exagero encontrar quem defenda Siquera Campos como o "construtor do Tocantins". Desde 1988, quando o estado passou a existir na Constituição Federal, o lendário Siqueira Campos fundou também a esperança de um povo esquecido no coração do Brasil. 
Palmas/TO foi criada no centro geográfico do estado do Tocantins. Mesmo existindo cidades mais estruturadas que pudessem vir a ser a nova capital do estado, optou-se (propositalmente) por construir a capital em uma região "neutra", mais central, à direita do rio Tocantins, na intenção de fortalecer questões políticas e administrativas. Se a escolha do centro não foi ao acaso, seria coincidência a Praça dos Girassóis ter sido construída justamente na região central de Palmas?

A cidade é inventada aos "moldes" de Brasília/DF. Uma cidade planejada, com ruas largas, arborizada, onde o comércio e progresso podem transformar a paisagem do sertão. (A história se repete?) Se analisar fotografias da construção de Brasília e de Palmas, veremos que a figura dos personagens Juscelino Kubitschek e Siqueira Campos estão em situações muito semelhantes. (Coincidência novamente?).

Com a ausência de referentes na cidade, inventa-se uma narrativa/memória a partir da criação de espaços, monumentos e símbolos. A Praça dos Girassóis é um dos principais lugares que compõe a identidade do povo palmense e que é sempre referendada pelos estudantes de Pedagogia como um lugar a ser descoberto (eu acrescentaria um lugar a ser redescoberto).
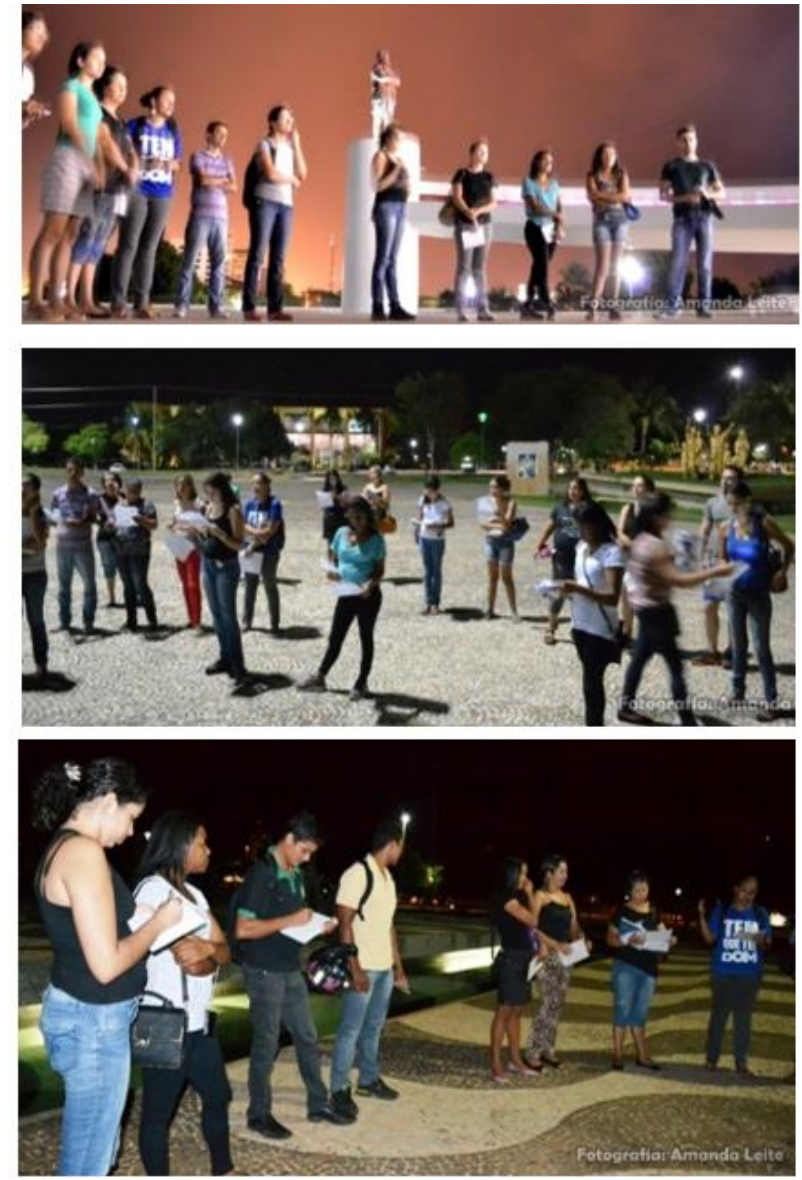

Fotos: Amanda Leite (Aulas na Praça) 


\section{O Palácio do Araguaia}

O principal prédio da praça recebe o nome de palácio. Curiosamente (ou por ser uma cidade planejada) Palmas carrega esta característica, ou seja, a de apresentar prédios imponentes, rotatórias amplas, estacionamentos espaçosos... O Palácio do Araguaia é a sede do governo do estado do Tocantins. Tem 4 pisos e cerca de 14 mil m². Estrategicamente foi construído no centro da cidade. O projeto das ruas do Plano Diretor Sul e Norte da cidade partem dele. O majestoso palácio tem arcos que homenageiam a igreja de Nossa Senhora do Rosário, localizada em Natividade/TO, para fazer menção às raízes históricas do estado. A tonalidade avermelhada dos arcos corresponde aos tons da terra e do cascalho do cerrado tocantinense. Além de exibir uma arquitetura moderna para a capital recém-inventada. O Palácio do Araguaia é outro cartão postal de Palmas.

Enquanto Siqueira Campos era governador do estado, construiu no sentido LesteOeste do palácio, um pórtico de entrada que se relacionava com os arcos e outro pórtico no sentido Norte-Sul. Cada pórtico tinha 5 metros de altura e 30 metros de largura. Siqueira também encomendou do artista visual carioca Maurício Bentes, dois frantipícios no formato de globo que faziam referência ao sol e ao Tocantins como promessa do futuro. Os globos foram feitos de "aço, em estrutura metálica dourada, medindo 50 metros, com diâmetro de 3,50 metros". Os globos refletiam a luz do sol e de qualquer ponto da cidade podia-se identificar o Palácio do Araguaia.

O sol também aparece no centro das bandeiras de Palmas e do Estado do Tocantins, como símbolo de energia. Quem chega recentemente a Palmas não sabe e nem mesmo encontra os globos na estrutura do palácio, pois, quando Marcelo Miranda venceu Siqueira Campos nas eleições para governar o estado do Tocantins, autorizou a retirada dos globos da fachada do Palácio. (Seria em decorrência de disputa política? Estética? Simbólica?) Como o governo geralmente se alternava entre Siqueira Campos e Marcelo Miranda, ora estava presente na praça, os girassóis, que dão nome ao local e os globos dourados, ora autorizava-se a retirada desses símbolos da praça para "arejar” a memória do povo.

O palácio abriga painéis em alto-relevo que contornam sua estrutura externa. São 144 placas de fibras de vidro esculpidas que narram a história da criação do estado do Tocantins desde o período geológico a $1^{\text {a }}$ missa - marco da implantação da capital. As placas revelam cenas do povoamento do estado, a vinda dos bandeirantes, a pedra fundamental, a relação com os indígenas, o discurso político esculpido de acordo com quem as encomendou. As placas são obras de Maurício Bentes. Há ainda dois painéis 
localizados no Hall de entrada do edifício - o Painel das Lutas e o Painel das Conquistas, ambos feitos pelo artista plástico DJ Oliveira, em pintura no estilo moderno, que mescla elementos do expressionismo e do cubismo, nas dimensões de $20 \times 20 \mathrm{~cm}$. Há outro símbolo religioso - o vitral - que representa os Reis Magos, o menino Jesus e o Batismo de Jesus feito por João Batista no rio Jordão. Da entrada do palácio avistamos o Centro Geodésico do Brasil e o símbolo da Rosa dos Ventos.
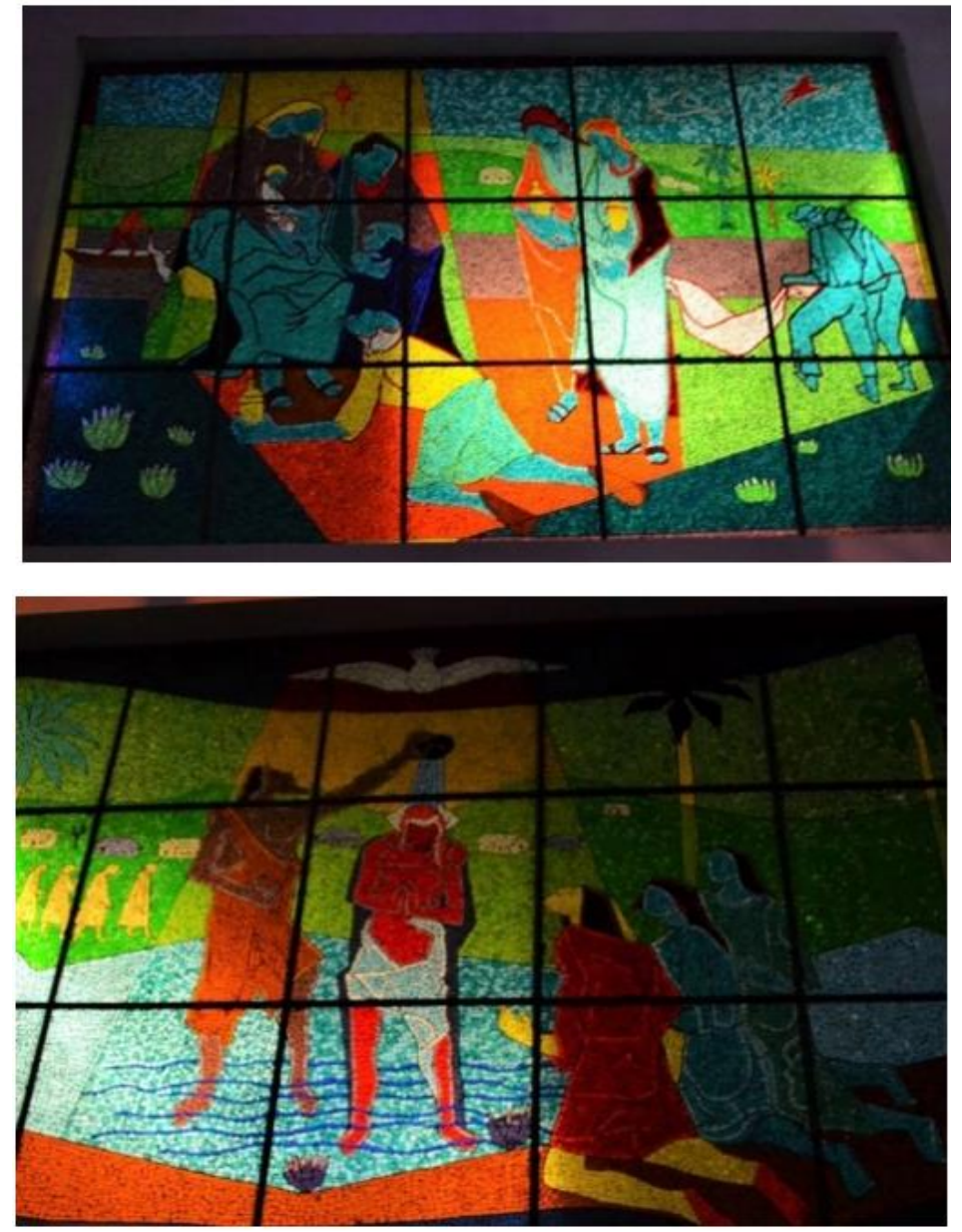

Fotos: Amanda Leite (Vitrais no interior do Palácio do Araguaia)

O discurso político hegemônico está presente nos painéis da entrada do palácio. Siqueira não precisou proclamar, mas os artistas por ele contratados conseguiram de algum modo evidenciar que as lutas e as conquistas reforçavam as promessas de um futuro melhor para o cerrado do Brasil. A questão é: como isso compõe o imaginário dos moradores de Palmas e dos estudantes de Pedagogia? Como os monumentos e símbolos continuarão a ser narrados? Surge um herói no cerrado! Um herói que luta, que desbrava, que faz greve de fome para a criação do estado! As cenas estampadas nas placas do exterior do palácio e também nas pinturas do Painel das Lutas e das Conquistas mostram a saga deste herói e a construção da capital. 
Se quisermos pensar a invenção desta cidade precisamos olhar com cautela o mito Siqueira Campos, "o construtor da identidade oficial do Tocantins", aquele que idealizou muitos dos aspectos sociais, políticos e culturais de Palmas/TO. O personagem que escreveu sua própria epopeia em destaque nas principais narrativas históricas, em materiais turísticos, em museus, em cadernos didáticos, em propagandas sobre a cidade e o estado. Símbolo da fé e da persistência. Homem-guerreiro-desbravadordonorte. Figura emblemática de livros que contam a história do Tocantins. Nas aulas que acontecem na praça, muitos acadêmicos se surpreendem com o legado lendário de Siqueira Campos: Professora, eu nunca tinha observado estes painéis! - Nossa! Quanta coisa que a gente não percebe! - Professora, eu não acho que o Siqueira quis contar assim... - Eu que nunca tinha entrado aqui no palácio! Olha tudo isso!

\section{A Praça Krahô}

Trata-se de uma praça pequena dentro da praça maior que é a Praça dos Girassóis. Embora a Praça Krahô seja uma importante homenagem às etnias indígenas tocantinenses recebe pouco destaque na praça, muitas pessoas da cidade não sabem da existência deste espaço, não conseguem localizá-lo na grande praça, até os estudantes indígenas do curso de Pedagogia se surpreendem quando descobrem a homenagem. Além disso, a Praça Krahô se mistura a outros símbolos cristãos como, por exemplo, O O Cruzeiro e o Monumento a Bíblia. Há também desenhos indígenas dispostos em outros lugares da Praça dos Girassóis, próximo à Rosa dos Ventos.

\section{O cruzeiro}

O cruzeiro foi o primeiro monumento histórico da capital. Está localizado na ala norte da Praça dos Girassóis. Feito de madeira Pau-Brasil, pelo artesão Arnildo Antunes. Foi instalado na praça no dia 20 de maio de 1989 e marcou a celebração da $1^{\text {a }}$ Missa em Palmas/TO. Curiosa passagem que nos faz lembrar a descoberta do Brasil a mais de 1500 anos. Na ocasião Frei Henrique Coimbra realizou a $1^{\mathrm{a}}$ missa do país. Temos no Cruzeiro um símbolo que inaugura não apenas à cidade, mas cria a memória popular do povo tocantinense. Nas fotos ${ }^{4}$ abaixo podemos comparar a primeira missa realizada em Palmas, a primeira missa realizada em Brasília e a primeira missa realizada em Goiânia.

\footnotetext{
${ }^{4}$ As imagens foram retiradas da tese de doutorado intitulada: Modernidades tardias no cerrado: discursos e práticas na história de Palmas-TO, (1990-2010), de autoria de Patrícia Orfila Barros dos Reis.
} 


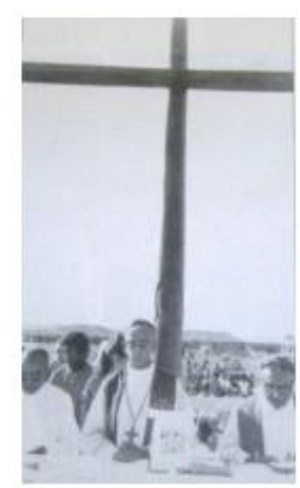

Foto 03: Primeira Missa em Palmas (1989)

Fonte: Jornal do Tocantins $(20 / 05 / 2000)$.

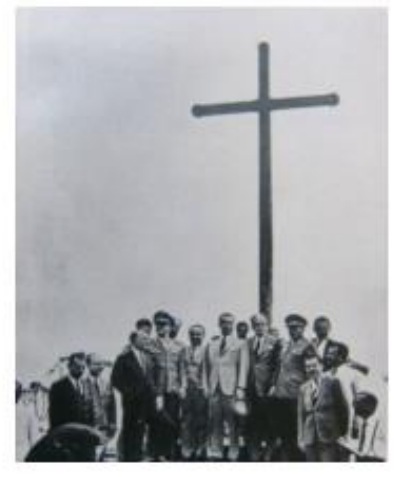

Foto 04: Primeira Missa de Brasília (1960)

Fonte: Revista Brasilia (1960).

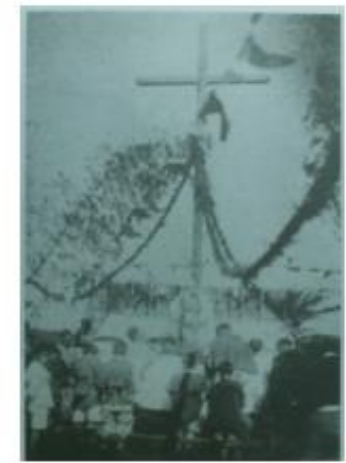

Foto 5: Primeira Missa de Goiânia.

Fonte: Teles (2005).

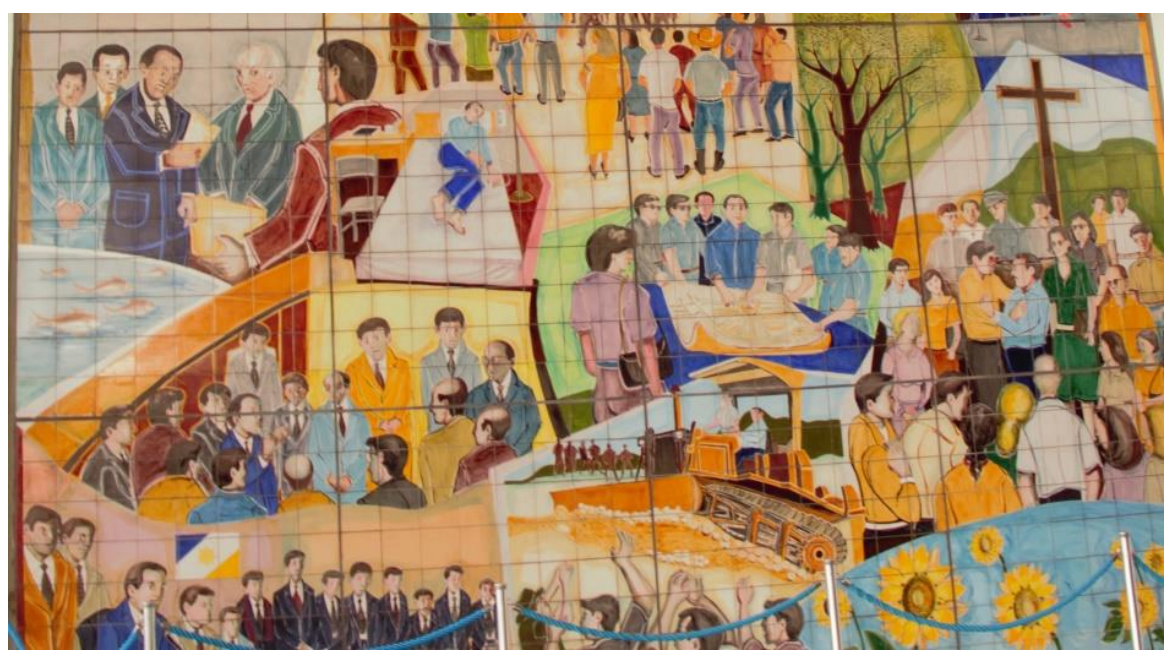

Foto: Amanda Leite - Painel da Conquista (interior do Palácio do Araguaia)
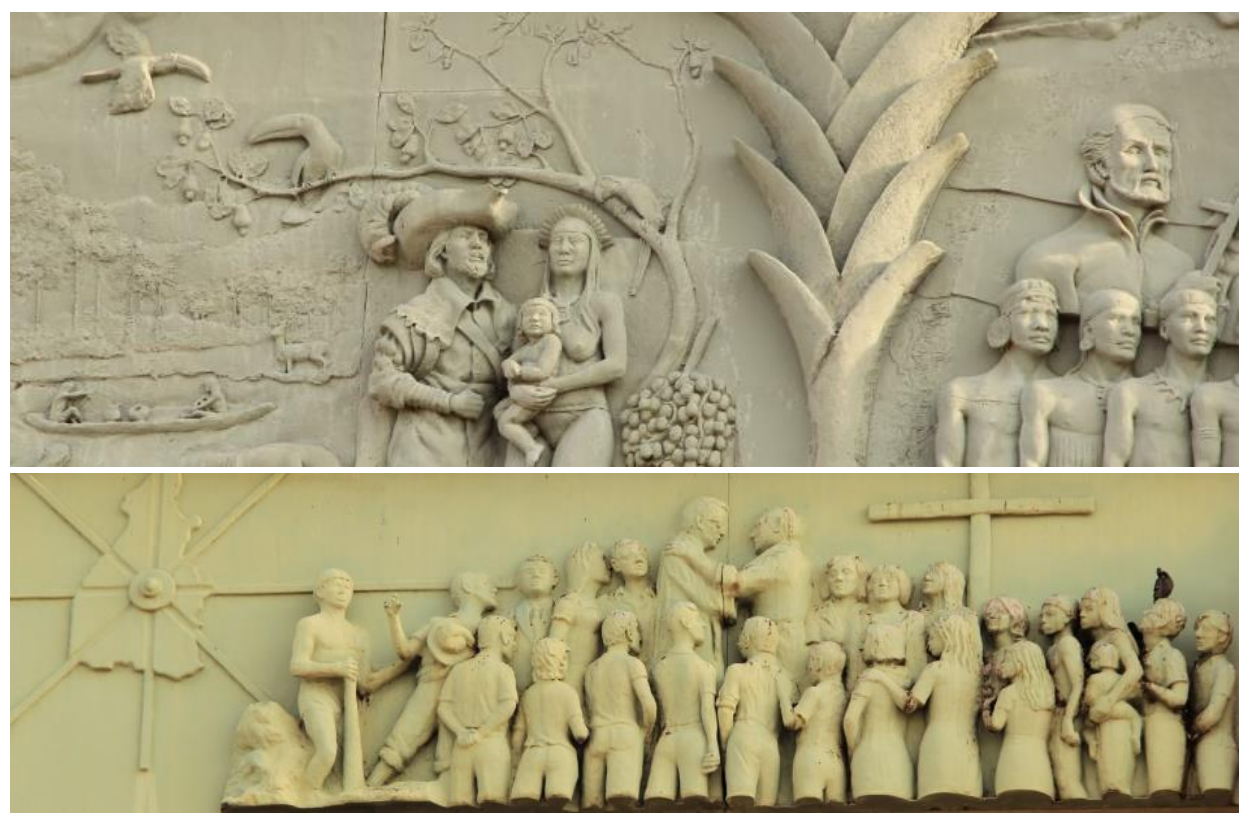

Fotos: Amanda Leite - Escultura (exterior do Palácio do Araguaia) 
O monumento Cruzeiro foi tombado como patrimônio histórico no ano 2000. Na $1^{\text {a }}$ missa de Palmas, estiveram lado a lado representantes indígenas da etnia Xerente e o desbravador Siqueira Campos. O que chama a atenção é essa sensação de algo que nos remete de novo à figura do índio e do colonizador... talvez seja por isso que esta imagem estampe um dos painéis externos do Palácio do Araguaia.

\section{Monumento à Bíblia}

Localizado na ala norte da Praça dos Girassóis, o Monumento à Bíblia está construído bem no centro da Rosa dos Ventos. A escultura mostra um homem de braços estendidos até o céu, sustentando nas mãos a Bíblia Sagrada Cristã. Para mim é um dos símbolos mais fortes e que causa mais polêmica no encontro com estudantes de Pedagogia. Digo isto, por causa da questão religiosa. Hoje no curso temos a presença de muitos estudantes indígenas, evangélicos e católicos. O monumento causa polêmica por parecer colocar o cristianismo acima de outras religiões, ou seja, enquanto as homenagens às etnias indígenas estão presentes em desenhos feitos por pedras portuguesas no chão da praça, o Monumento à Bíblia é feito em mármore e a escultura assume três degraus acima do chão. Esta mensagem também aparece esculpida nos painéis que cercam o exterior do prédio.

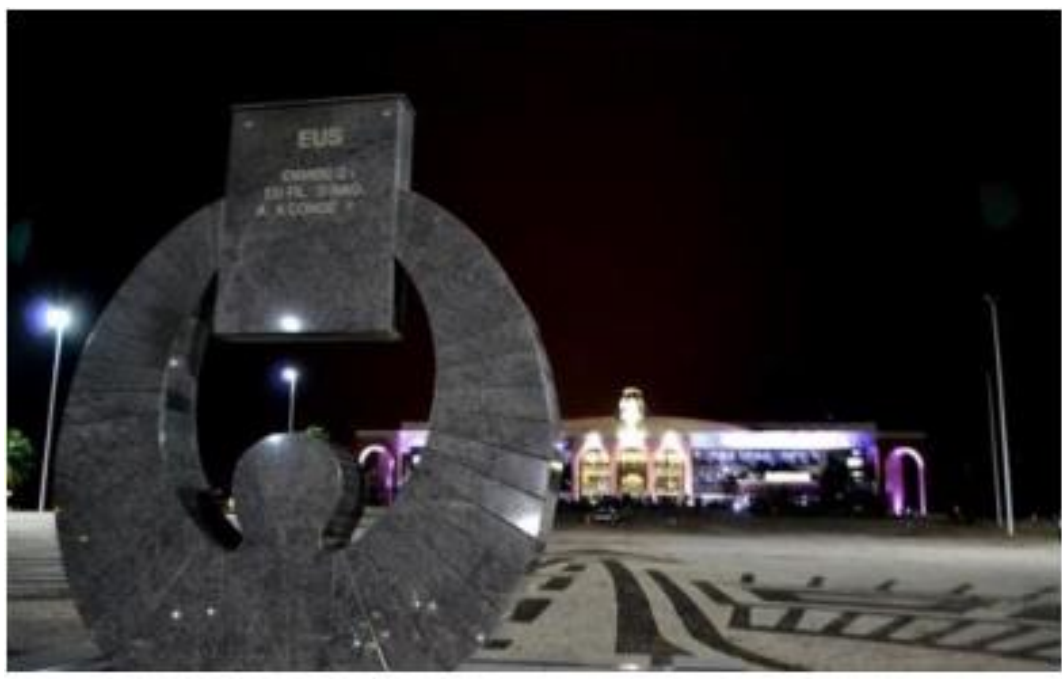

Foto: Amanda Leite - Escultura (exterior do Palácio 


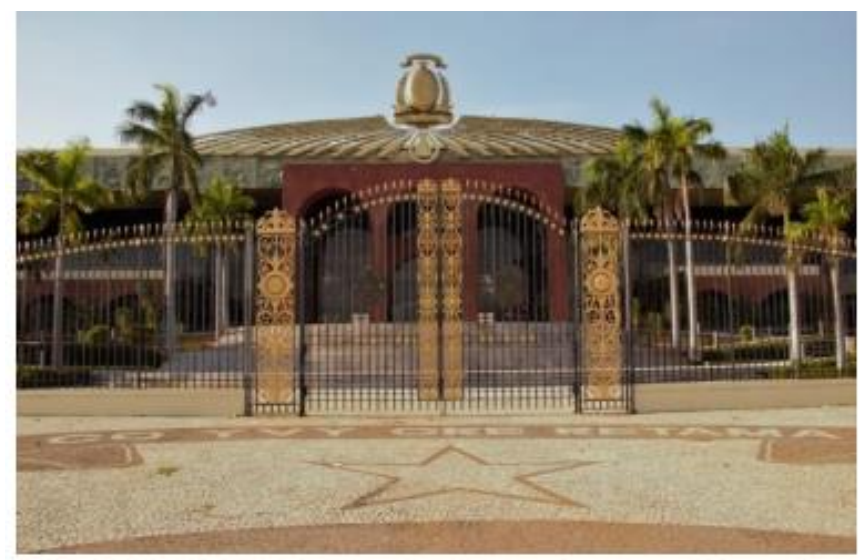

Foto: Amanda Leite - Portões Dourados (exterior

Para que você entenda melhor, o palácio tem dois lados iguais. Na ala Sul, existe um imenso portão dourado que está sempre fechado e no chão, em baixo do portão está escrito o lema do estado em língua tupi "Co yvy ore retama" que em português significa "esta terra é nossa", a frase também aparece no desenho do Brasão de Armas do Estado de Tocantins. Do outro lado, na ala norte, alinhado à porta de acesso principal do palácio localiza-se o Monumento à Bíblia. Ali, não há nenhuma barreira, nenhum portão. Do palácio se avista a escultura com o símbolo cristão. Na placa de entrada do Palácio do Araguaia temos a seguinte frase: "Daqui se pode olhar de frente o amanhã de uma terra despertada pelo ânimo dos que edificaram a obra que o tempo e a história consagraram com nervo das aspirações e centro da irradiação das decisões do povo". Um palácio aberto ao norte e fechado para o sul. Simbologia que nos faz pensar...

\section{Aula na praça: Pedagogias Culturais e pensamentos críticos ${ }^{5}$}

Como dito anteriormente, o termo Pedagogias Culturais se mostra como uma possibilidade conceitual para desenvolver pesquisas na área da Educação. Sei que muitas correntes epistemológicas adotam o termo e exibem percepções distintas. A definição

\footnotetext{
${ }^{5}$ Embora aqui tenhamos reduzido o referencial teórico unicamente afim de delimitar os interlocutores no diálogo sobre os Estudos e as Pedagogias Culturais, outras referências são igualmente importantes. Cito alguns clássicos que merecem nossa leitura: BHABHA, Homi K. O local da cultura. Belo Horizonte: Editora da UFMG, 1998. CANCLINI, Nestor Garcia. Culturas Híbridas: Estratégias para Entrar e Sair da Modernidade. Tradução Heloísa Pezza Cintrão, Ana Regina Lessa; tradução da introdução Gênese Andrade. 4 ed. 3. reimpr. São Paulo: Editora da Universidade de São Paulo, 1997. ECOSTEGUY, Ana C. D. Cartografias dos Estudos Culturais: uma versão latino-americana. Belo Horizonte: Ed. Autêntica, 2001. GIDDENS, Anthony. As Consequências da Modernidade. 2.ed. São Paulo: UNESP, 1991. HALL, S. Da diáspora: identidades e mediações culturais. Belo Horizonte: Editora UFMG, 2003. MARTÍN-BARBERO, Jose. Dos meios às mediações: comunicação, cultura e hegemonia. Tradução de Ronald Polito e Sérgio Alcides. 4 ed. Rio de Janeiro: Editora UFRJ, 2006. OROZCO, Guillermo. La investigación en comunicación desde la perspectiva cualitativa. Guadalajara, México: Instituto Mexicano para el Desarrollo Comunitario, 1997, entre outros.
} 
com a qual me identifico é a proposta de Steindberg (1997) que parte do campo dos Estudos Culturais para pensar a Educação. Assim, na medida em que aproximo diferentes temas da Educação posso articular, por exemplo, educação, comunicação, arte, cultura e distintos campos teóricos. Isto me interessa, especialmente ao pensar a formação em Pedagogia.

Trago a noção de Pedagogia Cultural não para me referir a uma pedagogia vinculada a escolas e/ou instituições de ensino, mas um movimento que aproxima a Educação dos Estudos Culturais do final do século XX e coloca a Pedagogia para pensar sentidos e significados nas relações de poder políticas e culturais que nos cercam. Um pensar que ultrapassa a noção de uma didática pedagogizante para produzir diferentes leituras nos processos educativos. Uma pedagogia que trabalha com artefatos culturais e produz subjetividades. Andrade e Costa (2015, p. 49) apontam que "a articulação entre pedagogia e cultura que embasa e nomeia este conceito foi assumida para tornar este reconhecimento mais explícito e salientar a qualidade cultural dos processos pedagógicos e das relações".

Não posso deixar de mencionar o importante trabalho de Henry Giroux (1999) que começou a adjetivar a pedagogia em relação à cultura e que também contribuiu com a proposta dos Estudos Culturais (EC). Assim como o conceito de EC é aberto, o conceito de Pedagogias Culturais também está em construção, sendo constantemente investigado, inclusive nas pesquisas acadêmicas em Educação.

Se os espaços sociais são também espaços de aprendizagem e de ensino, a Pedagogia pode propor a reflexão sobre Pedagogias Culturais como possibilidade de expandir a própria formação humana, oportunizando diálogos multidisciplinares, interdisciplinares e/ou transdisciplinares. Aulas realizadas em parques, museus, teatros e outros lugares sociais, assim como a Praça dos Girassóis, são alternativas que podem encontrar eco em discussões de áreas distintas.

No caso da perspectiva proposta pela aula de Didática, encontramos ressonância na disciplina de Metodologia do Ensino de Geografia, por exemplo, outra disciplina regular do curso de Pedagogia, em que se objetiva trabalhar também questões acerca das categorias geográficas, com especial atenção às categorias, lugar, cidade, paisagem e memória que, juntas, adensam o debate conceitual sobre a praça como dispositivo didático e pedagógico para a educação além de possibilitar pensar as relações que nos constituem neste espaço. 
A Pedagogia (ou as pedagogias) articula(m) encontros e sugere $(\mathrm{m})$ exercícios de pensar a produção de conhecimento. Conhecimento que se faz em movimento, algo diferente de qualquer definição pronta e acabada. Quando percorremos a praça e observamos os seus monumentos, o percurso revela uma pedagogia que produz efeitos e que também educa. Caminhamos pela praça, pensamos sobre ela, temos sensações, movemos nosso corpo, nossa mente, aprendemos e ao mesmo tempo construímos a aprendizagem no encontro com outros sujeitos. A praça, sua arquitetura moderna, suas narrativas simbólicas produzem em nós (moradores, estudantes e professores) interfaces com a educação.

A "ponte" entre a proposta educativa que a praça apresenta e as possibilidades de explorar suas perspectivas de ponto de vista das Pedagogias Culturais, somos nós quem iremos propor, pois talvez nem existiria aproximação pedagógica com este espaço social se não fosse forjado pela ocupação da praça como sala de aula. Tentamos responder a nós mesmos: qual é a nossa relação com a praça? Se fôssemos destacar um de seus monumentos e desenvolver um texto analítico a partir de nossas impressões considerando a relação com invenção e a narrativa sobre o Estado do Tocantins, o que teríamos a dizer depois de observar a praça com "outras lentes"?

As Pedagogias Culturais criam possibilidade para que o sujeito pense e aprenda com a própria experiência. Em nosso caso, buscamos ver a potencialidade pedagógica que a praça tem e que torna esta vivência mais atraente. Girox entende que a pedagogia crítica é aquela que se refere também a uma prática cultural. Assim acreditamos nos aproximar dos Estudos Culturais ao entender que estudantes e professores ocupam o lugar de pensadores públicos, ou seja, são figuras intelectuais que podem promover a articulação entre poder, cultura e aprendizagem. Este desafio contemporâneo nos permite reescrever a narrativa da praça, de seus símbolos e significados ou a narrativa de nós mesmos.

A praça é um artefato cultural presente no cotidiano da cidade que carrega em si (ao mesmo tempo em que denuncia) a presença de um herói lendário, a ideologia de um governante, discursos dominadores. Podemos até dizer que a praça produz uma pedagogia política que nos desafia a olhá-la sob muitas perspectivas, com um olhar mais crítico, na tentativa de perceber relações entre cultura, política, poder, espaço urbano, aprendizagem e educação, na busca por novos ares, mais narrativas.

Assim, entendemos que o ensino e a aprendizagem acontecem, em espaços sociais que ultrapassam os limiares das escolas, que chegam até as praças e monumentos da 
cidade. A praça é pedagógica e educativa, expõe os louros de uma época, as marcas da história de um povo que uma vez fora esquecido no norte deste país e que na atualidade ressurge como a capital da prosperidade e das conquistas.

O estudo de artefatos culturais nos ajuda a extrapolar o campo das pedagogias institucionalizadas (escolares) para pensar o sujeito numa dinâmica mais híbrida, que se deixa contaminar por diferentes concepções. O hibridismo provoca debates sobre as pedagogias que hoje estão dispostas na formação do sujeito. Assim, não apenas os materiais didáticos e/ou paradidáticos são interessantes de serem analisados, mas também o cinema, a televisão, a Internet, as redes sociais, revistas, jornais, programas de rádio, publicidade e outros dispositivos que conectados à comunicação atravessam o sujeito contemporâneo e que, compõe também as suas identidades e narrativas.

No percurso que fazemos na Praça dos Girassóis, o consumo de imagens fotográficas, por exemplo, é de certa forma um tipo de Pedagogia Cultural que ensina coisas ao mesmo tempo em que gera nos participantes um sentimento de pertença (pela imagem) da/na paisagem urbana. Fotografias tiradas e postadas nas redes sociais quase que instantaneamente à aula dão-nos pistas para explorar estas paisagens por infinitas leituras.

Se as Pedagogias Culturais acionam em nós outros modos de perceber o processo de ensino e aprendizagem, nas aulas que acontecem na praça os sujeitos se relacionam com a cidade e com as questões cotidianas que não necessariamente estão conectadas a educação escolarizada. Uma coisa é entender que as Pedagogias Culturais podem explorar outros modos de pensar o processo educativo (para além das pedagogias escolares), outra coisa é compreender que as Pedagogias Culturais também são dispositivos pedagógicos que educam o sujeito, produzem discursos e subjetividades. (E não é isto que vemos na praça o tempo todo?)

Enquanto dispositivo as Pedagogias Culturais podem nos conduzir a diferentes leituras e percepções. No exercício aqui proposto pensamos nossa experiência na relação com a cidade e suas narrativas. Nosso olhar se transforma diante da paisagem urbana. Este modo de operar o conceito de Pedagogias Culturais nos interessa, especialmente porque "o conceito se expressa e ganha significado mais pela materialidade daquilo que consegue mostrar empiricamente acerca de seus modos de operação do que pelo desenvolvimento ou reafirmação de uma teorização" (COSTA, 2015, p. 57). Ou seja, o percurso da praça forja subjetividades e a própria formação do sujeito. 
As Pedagogias Culturais nos aproxima ainda de outros materiais de pesquisa: revistas, materiais turísticos e cartões postais que forjam a subjetivação dos sujeitos ou mais precisamente, a noção de uma cidade que se deseja "vender/comprar" (a ideia da capital da alegria $\left.{ }^{6}\right) .$. Um investimento que aciona discursos, relações de poder e que transforma o modo como nos constituímos sujeitos neste espaço.

Ao trabalhar com imagens de materiais turísticos ou fotografias feitas pelos estudantes de Pedagogia, podemos encontrar diferentes possibilidades pedagógicas para a noção de paisagem/cidade. Qual é o viés educativo destas imagens? Qual é a mensagem que os materiais (produzidos por órgãos governamentais ou mesmo pelos estudantes de Pedagogia) desejam passar? O que consumimos? Estas imagens modelam em nós certas formas de pensar?

Não importa aqui procurar definir o conceito de Pedagogias Culturais à luz de determinada corrente de pensamento teórico, ao contrário, interessa dizer que as Pedagogias Culturais são potentes meios para investigar como produzimos conhecimento por meio de artefatos culturais. Encontramos aí alternativas para pesquisar imagens, monumentos e símbolos bem como articular estes pensamentos com a área da educação. As Pedagogias Culturais são conceitos inventados, que seguem em construção e investigação. Isto por si só já nos diz de sua potência.

Os materiais turísticos produzidos pelo governo do estado, as imagens exibidas pela mídia local ou por representantes da construção civil, mostram a cidade de Palmas como um lugar exuberante pelo potencial natural, como também um lugar novo, próspero para empreendedores além de muito agradável aos turistas. Não é por acaso que a prefeitura municipal tem usado e reforçado o slogan: "Palmas capital da alegria!". A narrativa sobre a construção desta cidade surge com a Praça dos Girassóis e segue reverberando leituras, olhares e pensamentos. O que apreendemos com estes encontros? Permita-me voltar então à questão inicial deste texto e perguntar: quando a aula de Didática acontece na praça, o que ela pode provocar?

\section{Bibliografia}

ANDRADE. Paula D. de. COSTA. Marisa V. Usos e possibilidades do conceito de pedagogias culturais nas pesquisas em estudos culturais em educação. Revista Textura, v. 17 n.34, mai./ago.2015.

\footnotetext{
${ }^{6}$ Capital da Alegria slogan usado pela Prefeitura Municipal de Palmas/TO em materiais publicitários. Palmas também é conhecida como: "A Caçula das Capitais"; "Princesinha do Brasil" e "Capital Inovadora do Tocantins".
} 
GIROUX, Henry A. Cultural studies and the politics of public pedagogy: Making the political more pedagogical. Parallax, 10 (2), 73-89, 1999.

HALL, Stuart. Identidade cultural e diáspora. In: Revista do Patrimônio Histórico e Artístico Nacional. Rio de Janeiro, IPHAN, 1996, p. 68-75.

STEINBERG, Shirley R. Kindercultura: a construção da infância pelas grandes corporações. In: SILVA, Luiz Heron da; AZEVEDO, José Clóvis de; SANTOS, Edmilson Santos dos (Orgs.). Identidade Social e a Construção do Conhecimento. Porto Alegre: SMED, 1997. p.98-145.

FIRMINO Eugenio Pacelli de Morais. Ensino de História, Identidade e Ideologia: a experiência do Tocantins. Dissertação de Mestrado. Universidade Federal de Goiás. Goiânia: 2003.

VILLAS BOAS, Marcos Antony. Projeto Frisa, A História do Tocantins contada em alto relevo nas vigas do Palácio Araguaia. Academia Tocantinense de Letras. Acadêmico Desembargador Marco Villas Boas, Palmas, 20 de dezembro de 2002.

Data de Recebimento: $17 / 10 / 2017$

Data de Aprovação: 05/07/2018 


\section{Para citar essa obra:}

LEITE, Amanda M. P., A praça é nossa! Narrativas cotidianas e pedagogias culturais In: RUA [online]. Volume 24, número 2 - p. 413-429 - e-ISSN 2179-9911 novembro/2018. Consultada no Portal Labeurb - Revista do Laboratório de Estudos Urbanos do Núcleo de Desenvolvimento da Criatividade.

http://www.labeurb.unicamp.br/rua/

Capa: foto de Amanda Leite - Painel da Conquista (interior do Palácio do Araguaia)

\section{Laboratório de Estudos Urbanos - LABEURB}

Núcleo de Desenvolvimento da Criatividade - NUDECRI

Universidade Estadual de Campinas - UNICAMP

http://www.labeurb.unicamp.br/

\section{Endereço:}

LABEURB - LABORATÓRIO DE ESTUDOS URBANOS

UNICAMP/COCEN / NUDECRI

CAIXA POSTAL 6166

Campinas/SP - Brasil

CEP 13083-892

Fone/ Fax: (19) 3521-7900

Contato: http://www.labeurb.unicamp.br/contato 